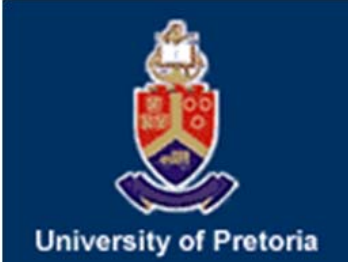

University of Pretoria Department of Economics Working Paper Series

The Short Term Economic Impact of Levying E-Tolls on Industries Francois J. Stofberg

University of Pretoria

Jan H. van Heerden

University of Pretoria

Working Paper: 2015-27

May 2015

Department of Economics

University of Pretoria

0002, Pretoria

South Africa

Tel: +27 124202413 


\title{
The Short Term Economic Impact of Levying E-Tolls on Industries
}

\author{
Francois J Stofberg and Jan H van Heerden*
}

April 23, 2015

\begin{abstract}
$\mathrm{TERM}^{1}$ is used to analyse the short term regional economic impact of an increase in industries' transport costs when paying E-Tolls. Marketclearing and accounting equations allow regional economies to be represented as an integrated framework; labour adjusts to accommodate increasing transportation costs, and investments change to accommodate capital that is fixed. ${ }^{2}$ We concluded that costs from levying E-Tolls on industries are relatively small in comparison to total transport costs, and the impact on economic aggregates and most industries are negligible: investments $(-0.404 \%)$, GDP $(-0.01)$, CPI $(-0.10 \%)$. This is true even when considering costs and benefits on industries as well as consumers. Industries that experienced the greatest decline in output were transport, construction, and gold. Provinces which are closer to Gauteng, and have a greater share of severely impacted industries, experienced larger GDP and real income reductions. Mpumalanga's decrease in GDP was $17 \%$ greater than Gauteng's.

JEL classifications: C68, L91, R11, R48

Keywords: Computable General Equilibrium Models, Regional Economics, Policy Modelling, Transport Cost
\end{abstract}

\section{Introduction and Methodology}

\subsection{E-Tolling in South Africa}

Gauteng's Provincial Government (Department of Transport, 2011) and Pienaar (2011) state that an inadequate transport network in Gauteng is one of the key constraints to economic growth. The four phased Gauteng Freeway Improvement Plan (GFIP) was introduced as a solution to the inadequate network. Phase 1 involved a R19.5 billion upgrade to 185 kilometres of freeways in Gauteng (Department of Transport, 2011), and the introduction of E-Tolling. Tolling had to be equitable, affordable, traffic attracting and efficient; as a result directional E-Tolls were introduced (Department of Transport, 2011). These tolls

*University of Pretoria 
operate as an Open Road Tolling (ORT) system to limit the impact on road traffic; the system collects tolls 10 kilometres apart and does not require vehicles to slow down or stop. E-Tolls are levied in one of the provinces of South Africa, but as our research has shown, influence the entire economy; directly through other province's use of the GFIP and indirectly through Gauteng's share of total economic activity. For this reason a multi-regional model of the country is utilized to measure cross-regional economic effects. ${ }^{3}$

\subsection{Research on E-Tolling in South Africa}

The majority of research on the effect of E-tolling on the economy tend to show partial equilibrium effects and are narrowly focused with weak assumptions. Most of these theoretical models also assume that tastes and technology are uniform or are represented by only a few individuals or firms.

An assessment of the likely impact of the GFIP on the regional as well as national economy was conducted by Economists.co.za (2011). The nature of their analysis is analytical and limited in the observed variables chosen. In their research they estimated that the toll incidence on the commercial road freight industry could amount to an equivalent $30 \%$ company tax increase. TERM modelling is not limited in this manner, and this paper has found that, except for the gold industry, transport cost increases on industries are small in comparison to total transport costs. Economists.co.za (2011) estimated that consumer price inflation (CPI) would increase by approximately $0.4 \%$, and Standish et al. $(2010)$ concluded that consumer prices would increase between $0.28 \%$ and $0.31 \%$, depending on LSM-group. This paper found that even when considering costs and benefits to both consumers and industries, CPI would only increase with $0.12 \%$ in the short term. As suggested in Economists.co.za (2011), Standish et al. (2010) did a cost benefit analysis of the GFIP over a twenty year period. Their results showed that on an aggregate level, benefits to road users are greater when driving on upgraded roads and paying E-tolls, than not upgrading, but simply maintaining the road network. The aim of this study was to determine the short term economic effects of the direct increase in transport costs on industries, as a result of levying E-Tolls. However, we briefly consider the short term case of direct and indirect costs and benefits on industries as well as consumers, as originally outlined in Standish et al. (2010).

Using a general equilibrium model to forecast an increase in transport cost, the following particular advantages arise: the model captures not only the direct impact of the change, but also a full system wide pattern of indirect effects (Horridge, 1999), and the so called multiplier effects between all regions and commodities of the model. This introduces a more accurate measurement of the macro-economic implication of levying E-tolls on industries. Other di-

\footnotetext{
${ }^{3}$ Some multi-regional models that have been developed include; Bröcker et al., 2010; Das et al., 2005; Horridge and Wittwer, 2008; Ishiguro and Inamura, 2005; Latorre et al., 2009; Li et al., 2009 and Ueda et al., 2005. Donaghy (2009) is carrying out a survey of literature that follows this direction. This type of multi-regional models deal with cross-country analysis, those that focus on disaggregating one country into separate economies follow later.
} 
mensions can also be explored with a general equilibrium model; the effect on unemployment, income distribution and social equity, changes in consumption, investment patterns, and so on.

\subsection{Transport Costs in Regional Modelling}

Haddad and Hewings (2004) evaluated the structural impact of Brazilian policy developments which caused a reduction in transport costs and found that regions in the Centre-South parts of Brazil had greater real GDP growth rates. Also, the welfare of households in less developed regions who had access to producing regions were better off. Haddad and Hewings (2004) analysed parameter sensitivity based on Domingues et al. (2003), and found that both short and long-run simulated parameters were robust. Steininger et al. (2006) found that levying transportation costs had a greater negative effect on wealthier households and those users who make the most frequent use of the roads. Their results showed that if toll revenues are used to lower labour taxes the negative effect on GDP and employment can be negated. As suggested by Haddad and Hewings (2004) we introduced a more comprehensive approach by linking TERM's system with a model of the transportation shippers' market. This was done by calculating costs incurred for each industry in each region as they make use of the GFIP and henceforth have to pay E-tolls.

The remainder of this study is organised as follows. Section 2 considers the TERM model whilst Section 3 outlines the process of estimating the increase in industry transport cost when E-Tolls are levied. Section 4 explains how transport costs are applied in TERM and Section 5 abbreviates on the causal relationship that follows from increasing industry transport costs. Section 6 describes the TERM database and calibration, in Section 7 we explain the simulation process and results, and finally we conclude our finding and suggest further research in Section 8.

\section{TERM Modelling}

Dixon et al. (1982) initially introduced the large-scale CGE model, named ORANI. Models of this nature consist of social accounting matrices (SAMs), and use input-output tables on the premise that the whole economy is balanced in value. CGE models combined the efficiency of linearised algebra of Johansentype models with the accuracy of multi-step solutions. Through its simplistic nature it allows for the development of more disaggregated, elaborate and dynamic models. A typical result from CGE models estimate percentage changes of endogenous variables after a policy has been implemented. The bottom-up approach in TERM allows simulations with region-specific price effects, and the modelling of imperfect factor mobility between regions and sectors (Horridge, 2011).

This study builds on work originally done by Horridge (2003) and later in Horridge (2011), as simulations are run using the bottom-up TERM model 
which allows us to analyse policy effects on 10 regions, 27 sectors and 27 corresponding commodities in South Africa. ${ }^{4}$ To achieve this purpose, several assumptions were made. Firstly, ten regions, representing the nine provinces of South Africa as well as a region representing the rest of the world, are analysed. ${ }^{5}$ Secondly, individuals are modelled as utility maximizers who face a discrete number of choices. Through the cost of travel and regional layouts the pattern of labour and industrial activity is influenced. Thirdly, national input-output data for 2005 and regional data are combined to aggregate the South African economy into separate regions, commodities and industries.

\subsection{TERM's Sourcing Mechanisms}

Horridge et al. (2005) and Horridge (2011) illustrate the various substitution possibilities of the model (also referred to as "nests") and shows the TERM model's data sourcing ability. To illustrate we use a simple example of a single commodity (Meat), in a single region (Eastern Cape), used by a single predefined user (Households).

Households choose through a constant elasticity of substitution (CES) type specification, to source a particular commodity (meat), domestically or abroad. A common value for the elasticity of substitution between imported and domestically supplied commodities, is defined as two $(\sigma=2)$, (Horridge, 2011). Demand for commodities is guided by prices that are user-specific and found in the PUR-matrix which is a summation of the TAX and USE-matrices. The next step involves domestic demand for the commodity (meat), in a specific region. Demand in each region is summed over all users to obtain aggregate regional demand USE_U; summing over the user index $u$. This matrix allows for a price that includes trade and transport costs (basic + margin costs), also referred to as the delivered-value in the DELIVRD-matrix, which further shows how USE_U is disaggregated between regions of origin.

A CES specification (with a substitution elasticity of four, as suggested by Horridge, 2011) is used to allocate domestically demanded meat from the various regions. Decisions on this level are accepted for all users as if wholesalers and not final demanders decide where meat would be sourced from. This level is therefore without the user subscript $u$, implying that in Gauteng the proportion of meat that comes from Limpopo is the same for households, intermediate users as well as other final demanders. The application of a CES specification allows regions with lower production costs to increase production relatively more than other regions, in an attempt to increase their market share. It is important to remember that sourcing decisions are made on the basis of delivered prices; even if farmers keep prices fixed, a change in transport costs (or other margin costs) will affect regional market shares.

\footnotetext{
${ }^{4}$ Other TERM publications include both papers by Glyn, W. and Horridge, M. (2007), Horridge et al (2005), Haddad, A.M. and Hewings, G.J.D. (2004), Wittwer (2003)

${ }^{5}$ These provinces include the Eastern Cape, Free State, Gauteng, Kwazulu-Natal, Limpopo, Mpumalanga, Northern Cape, North West and the Western Cape.
} 
Delivered meat from Limpopo follows a Leontief composite of basic, margin and trade costs. Margin costs are derived from a combination of factors sourced from the level by which data is disaggregated and include origin, destination, commodity and source, which influence its share of the commodity's delivered value. Commodity regional-pairs that are far apart, heavy or bulky, will have a transport cost with a higher share of delivered value than those region-pairs that are not (Horridge, 2011).

Under the Leontief specification, substitution is allowed between Road and Retail as well as Road and Rail margins. Switching between Road and Rail is also allowed as proposed by Wittwer (2003). Taken at an aggregate level, the elasticity of substitution for road margins levied on meat, passing from Gauteng to the Eastern-Cape lies between 0.5 and 0.1, as suggested by Horridge (2011). Horridge (2011) explains that these are common CES amounts used for road margins and assume that a region applies the same CES to all commodities transported, applying equally to the origin, destination and transit regions. An elasticity of substitution of 0.5 would be a good fit for transport industries such as trucking services, which can relocate depots to cheaper regions. Other industries, particularly those in retail, would see a more fitting CES of 0.1; substitution is less, due to larger sourcing from the destination region itself. Sourcing commodities from the same region as its destination, reduces total transport costs (Horridge, 2011). TERM modelling also allows for the ability to involve price competitiveness of freight services among regions.

\subsection{TERM's System of Equations}

TERM shares similar equations with CGE models, where producers choose to minimize costs according to a CES-type production function of nesting assumptions. Producers apply a production function to determine the correct combination of intermediate commodities and primary factor inputs. Horridge (2011) explains how TERM assumes that demand for primary factors and intermediate inputs, follow a Leontief-type nesting structure in proportion to the industries' output. Each of these high-level aggregate decisions are made through a CEStype specification. Primary factor aggregates follow a CES composite of land, capital and labour whereas intermediate inputs follow a CES composite between the various commodities in the economy. Within each of these primary factor CES specifications, labour follows a CES specification between the various skill (occupancy) groups. Commodities follow a CES composite between the two sources: domestic or imported. Finally, a constant elasticity of transformation (CET) mechanism is calibrated from the MAKE-matrix, to transform outputs from intermediate goods and primary factors into final goods. Wittwer (2003) and Horridge (2011) distinguish regional behavioural equations used in TERM - these are additional to the standard equations of CGE modelling in the ORANI-school (Dixon et al. 1982). ${ }^{6}$ Regional equations include regional

${ }^{6}$ Core model equations are best represented in standard equations in Steininger, Freidl and Gebetsroither (2006) and a full explanation of equations used in CGE modelling is given in Lofgren, Lee Harris and Robinson (2002). TERM model equations are best illustrated as 
demand, supply, sourcing and revenue equations, amongst others.

\subsection{More TERM Features}

Wittwer (2003) and Horridge (2011) explain that each region's exports to the rest of the world also follow a CES specification. Household demand follows a LES specification between subsistence and luxury goods and services; and on a regional level, household consumption can be linked to income. It is important to note that closure flexibility applies separately on national and regional levels, Horridge (2011). For this reason we can allow regional consumption to follow wage income through some rule, $C_{T}=F_{T} * W_{T} * \gamma$ where $F_{T}$ is a particular region's propensity to consume and we introduced $\gamma$, a slack variable that adjusts to satisfy the trade constraint on the national budget. Investment and government demands for commodities are exogenous and a variety of model closures are possible. For our analysis a short-run closure is chosen in which capital stocks and land endowments are held fixed; changes in the production structure are then driven by labour. Labour is fully mobile between sectors but only partially so between regions.

\section{Industry Transport Cost Increases from levy- ing E-Tolls}

We estimate the increase in industries' transportation cost as well as the percentage increase on total transportation cost for commodities from each province with the introduction of E-Tolls. To do this we use commodity flow data of Gauteng as provided by the National Freight Flow Model (NFFM) and the Commodity Flow Model (CFM), outlined in Havenga (2007) and later modified in Havenga (2013). The commodity flow data consists of 3.4 million routes each consisting of commodities transported, origin, entry and exit points into Gauteng, end destination, base tonnage, and route distance, amongst others. These routes represent annual commodity flows from all provinces in South Africa as well as neighbouring countries to, through and from Gauteng. The NFFM utilises the South African National Road Agency's (SANRAL) Traffic Count Yearbooks compiled by Mikros Traffic Monitoring, as well as actual freight flow data obtained from Spoornet. Havenga (2007) explains how, by utilizing these sources, the NFFM produces the most complete surface freight data in South Africa that includes modal market share, flow data, and road tonnage for a list of corridors, metropolitan and rural areas.

A Commodity Flow Model (CFM) was developed to fill the gaps of the NFFM; disaggregating total freight transported into commodity flows for 73 commodities over different typologies (354 magisterial district levels) in South Africa. The CFM was later adapted to include gravity modelling which is most commonly used in international freight flow models, based on the premise that

standard equations in Wittwer and Horridge (2010). 
demand and supply drive the flow of commodities between origin and destination (Havenga, 2013). In addition to the CFM a Freight Demand Model (FDM) allocates different vehicle types to each commodity for various origin-to-destination routes or corridors; this allowed us the possibility to determine the vehicle class, which is required to estimate the cost at each gantry. Furthermore, Transnet's Transportation Model (TTM) adapted the CFM and disaggregated the magisterial district levels into 977 unique stations: origin, destination and entry/exit points into Gauteng. By simulating these commodity flows on Google Maps we were able to calculate the additional cost from levying E-Tolls for each commodity from each province transported to, through or from Gauteng.

From the station assumptions we obtained coordinates for each station to simulate commodity flows on Google Maps, utilizing each routes' entry and exit point into Gauteng. Google Maps automatically assumes the shortest kilometre route, taking into account time travelled. E-Toll gantries were overlaid on the simulations in order to estimate the additional cost incurred for each commodity flow. For our purposes we assumed that all users are registered E-Toll users as this will most accurately represents the direct cost of levying E-Tolls.

Utilizing the vehicle types that apply to different routes or corridors and commodities in the FDM, a more accurate cost could be estimated as gantry costs differ according to vehicle class. We also employed the Road Freight Association's (RFA) Vehicle Cost Schedule (VCS, 2013) in conjunction with the FDM to differentiate the payload and load factor for each vehicle type of each commodity from a given province. In total there were approximately 780000 unique routes to, through and from Gauteng that represent 73 commodities and 977 unique stations. Combining the payload and load factor data with the CFM's total tonnes of each commodity transported per route, the number of times each commodity per province is transported on a certain route or corridor is estimated by applying:

$$
\text { Routes Travelled }=(\text { Base Tonnage } / \text { Payload }) *(1 / \text { Load Factor })
$$

Important for our analysis is the percentage increase in total transport costs in which case total transport cost per commodity from each province to, through and from Gauteng had to be estimated. By combining the RFM with the RFA's VCS (2013), a cost per ton $/ \mathrm{km}$ was obtained specific to the vehicle used, commodity transported and province of origin. The cost per ton $/ \mathrm{km}$ is then multiplied by the distance of each commodity flow (obtained from the NFFM and CFM), the amount of tonnes transported, and adjusted by the load factor (to take into account return costs), to obtain Total Cost (TC):

$$
T C=\text { Cost per Ton } / K m * \text { Dis } \tan c e * \text { Tonnes } *(1 / \text { Load Factor })
$$

By aggregating the 73 commodities into the 27 commodities of the TERM model, we were able to estimate the total transportation cost (TC), total gantry cost (TGC) and percentage increase in transport costs for each commodity after the introduction of the E-Tolls. ${ }^{7}$ The percentage increases were then simulated

\footnotetext{
${ }^{7}$ Province and commodity specific increases have also been estimated and are available upon request.
} 
as transport cost increases of the corresponding industries in TERM. Amongst those commodities Gold (10.9\%), Clothing, textiles and footwear (1.78\%), Electrical equipment $(1.57 \%)$ and Metal and machinery (1.37\%) experienced the largest transport cost increases. We concluded from our findings that the increase in transport costs that industries experienced, after the introduction of E-Tolls were relatively small in comparison to total transport costs.

\section{Transport Costs in TERM}

By adjusting an exogenous transportation cost parameter $(t c p)$ in a similar manner as Sakamoto (2012), an increase in transportation cost is introduced into the TERM model. ${ }^{8}$ The purchasing price industries pay $(P P I)$ for example is estimated by multiplying the price final users pay $(P D)$ with the transportation cost $(t c p)$. Here, tcp is an exogenous transportation cost parameter that decides the rate of the transportation cost, and is calculated from the social accounting matrices (SAM) database, as follows:

$$
t c p_{r, s}=\frac{P D_{r, t r a n s} P C_{r, s, t r a n s} 9}{\sum_{i i} P D_{r, i i} P C_{r, s, i i}}
$$

Parameters vary by region and industry and through the summation of all transportation costs the demand for transportation can be derived. Equations used to specify the prices that users pay, also referred to as purchaser's prices, impose zero pure profits in the distribution of commodities to various users (Haddad and Hewings, 2004). The purchaser's price paid for commodity $i$, that was transported from a certain region to its final user, equate to the sum of its basic value and the costs of the relevant taxes and margin commodities (Haddad and Hewings, 2004). Margin commodities consist of trade and transport commodities that are used to facilitate trade between users (also transfer costs) and commodity movements between users and regions; from points of production or entry to either domestic users or ports of export (Haddad and Hewings, 2004). These margins are produced at the point of consumption, whereas margins on exports are produced at the point of production. Haddad and Hewings (2004) explain that the demand for margins, both trade and transport margins, are proportional to the commodity movements with which the margins are associated and some technical change. Margin demand in TERM, similar to B-MARIA in Haddad and Hewings (2004) is equated as follow, in linearised form:

$$
\begin{gathered}
X M A R G(i, s, q, r)=A M A R G(i, s, q, r) * \\
{\left[\eta(i, s, q, r) * X(i, s, q, r)^{\wedge}(\theta(i, s, q, r))\right]}
\end{gathered}
$$

\footnotetext{
${ }^{8}$ The database includes aggregated input-output data as well as regional transactions. This allows for calibrating of the transportation cost parameter of which the transportation sector includes all modes of transportation, and by increasing transportation costs, trading costs increases.

${ }^{9} \mathrm{Raw}$ data of the transportation sector is used in the SAM database. The suffix "ii" is indicative of the sector. A further explanation on production; "i1" indicates the sector that has a constant return in production, "i2"a sector with an increasing return in production.
} 
where $\operatorname{XMARG}(i, s, q, r)$ is the margin $r$ on the movement of commodity $i$, that was produced in region $r$ to be consumed in region $q$; $A M A R G(i, s, q, r)$ is the technology change component that allows changes in the implicit transportation rate. This component is commodity-specific between origin and destination pairs; $\eta(i, s, q, r)$ is the margin rate on specific movements; $X(i, s, q, r)$ is the movement of commodity $i$, that was produced in region $r$ and consumed in region $q$; finally $\theta(i, s, q, r)$ is a parameter used to introduce the economics of scale in transport commodities. During model-calibration this parameter is set equal to one for every movement.

\section{The Causal Relationship in TERM}

When transport costs increase, the use of transportation services (margins) per unit of output increases, which initially increase transport service output (Haddad and Hewings, 2004). However, moving commodities become more resource intensive, restricting capital and labour. Capital and labour which become scarcer add upward pressure on primary factor prices, which are passed on to commodity prices (Haddad and Hewings, 2004).

Price effects of higher composite commodity prices fall on producers, investors as well as households. Producers experience increased production costs which in turn reduces their competitiveness. Investors anticipate lower returns as the cost of producing capital increases, and households experience relatively lower real incomes and fewer consumption possibilities follow. Lower real income reduces domestic demand and a reduction in firm competitiveness reduces external demand, reducing overall output in the economy. Reduced output lowers the demand for primary factors that cause prices of those factors to decline. Lower primary factor prices create an accompanying expectation that the prices of domestic commodities will also decrease (Haddad and Hewings, 2004). In our results most commodities experienced price increases which indicate that on an aggregate level the increase in costs outweighed the decrease in demand.

Haddad and Hewings (2004) also explain how the effect of second round price changes go in both directions - decreases and increases, where the net effect is determined by the relative strength of three major countervailing forces. These countervailing forces include two substitution effects (direct and indirect), and one income effect. The net change in prices will depend on the magnitude of these countervailing forces.

\section{CGE Database and Calibration}

Before using TERM to model an increase in transport cost, a base solution of the model is constructed; this process is referred to as calibration. Calibration infers unknown or unobservable parameters and variables from those that are known. A standard model solution was implemented in this study: exogenous variables being observable (tastes and technological shift variables), and endogenous vari- 
ables, referring to unobservable or behavioural parameters (genuine data and judgemental priors). Sakamoto (2012) and Horridge (1999) give a list of typical exogenous and endogenous variables that are used in CGE as well as TERM modelling.

The model is calibrated using the database and except for elasticity's, which is selected based on literature, all parameters and exogenous variables are estimated or decided upon by the database and the model's maximisation conditions. The number of firms in a specific industry to which small firms belong is set equal to one; this simplifies calculations and allows the parameter to be used as a relative measure. In order for this assumption to hold, the equal quantity and prices small firms encounter, become equal to the summed total in the data. Regarding the solution method in TERM, computation is also performed by regarding it as the summed total, as it is sourced from the data. The agglomeration effect on industries between regions can be seen in the change of industry input as well as output, after a shock that increases transportation costs of industries, has been simulated.

The TERM database starts with the South African Reserve Bank's (SARB) Input-Output (IO) tables of 2005. These tables distinguish between sectors in the South African economy and are converted into a standard single-country format used in CGE models. In a following step, on the national level, standard industrial sectors are expanded in an attempt to avoid infelicities of classification. Creating a suitable dataset for TERM's regional modelling, region and user-defined share-estimates were estimated. Region and user-defined share estimates, which indicate each region's share of national activity for a given user and industry, were required in order to develop a full input-output table for each region. These shares include: industry shares, industry investment shares, household expenditure shares, international export and imports share, and government's share of consumption. Further, to model the effect of a transport cost increase on industries that use the GFIP and pay E-Tolls, a region and userdefined share-estimate of the cost levied was estimated. A thorough description for the methods used to estimate this share-cost is given in Section 3. Applying these shares to the national CGE database we can calculate the USE, FACTOR and MAKE-matrices.

The main data sources that were used to split industries according to their share include: (1) Household Income and Expenditure Survey 2005 (STATSSA), (2) Employment data of the QES and QLFS of STATSSA, (3) Census 2001 data from STATSSA, (4) Regional manufacturing, mining, retail and-wholesale production and sales as well as electricity data, supplied in various publications of STATSSA, (5) Regional demand and supply totals from the Development Bank, (6) Import and export demand from South Arica's Department of Trade and Industry.

\subsection{Region-Specific Technology and Output Mix}

Industry technologies do not vary by region when applying regional output shares to the national dataset. Although the South African TERM-model is only 
applied to 10 regions as opposed to the 52 regional TERM model of Australia in Horridge (2011), assuming equal industry technology over regions would therefore not be as crude. Solving the issue of regional technology, Horrdige (2011) distinguishes separate inner-sectors which each produce some commodity that shares certain characteristics to another. These inner-sectors were applied to industries that had a uniform technology across regions. Prior to the simulation these inner-sectors were aggregated together whilst commodities of these sectors were left separate. Complications in this process are avoided by assuming a diagonal MAKE-matrix (Horridge, 2011). The result is a varying input technology for the particular industry, across region and commodities. From this, land and labour inputs can be switched between commodities of a similar sector to allow estimation of the change in land usage, Horridge (2011).

\subsection{Data and the TRADE-Matrix}

The TRADE matrix is a 27 x 27 sub-matrix of each commodity, domestically supplied or imported. Very little inter-regional trade data is available for South Africa, much like in Australia in the case of Horridge (2011). For this reason the same gravity formula was applied to construct trade matrices, similar to Horridge (2011). The gravity formula assumes that trade volumes follow an inverse power distance which allows constructed trade matrices to align with pre-determined row and column totals. ${ }^{10}$

\section{Simulation and Results}

We apply the TERM model's system-wide representation of regional economies to analyse the short term economic effect of levying E-Tolls on industries. Our simulation assumes the case where transportation costs of industries are increased (the shock) by the levying of E-Tolls on the GFIP. Tolls are levied according to road usage that varies among industries in the different provinces of South Africa, as estimated in Section 3 of this paper. The results of the simulation indicated: (1) changes in the industrial structure, (2) changes in household income and spending and (3) changes in macro-economic variables of individual provinces as well as South Africa as a whole. From our short term closure, capital is assumed fixed and therefore cannot be moved across regions, unlike labour, which is moveable within industries and across regions. Reporting changes in labour is therefore important, and specific emphasis is also placed on industry output and regional income.

\subsection{Initial Result Assessment}

The following changes in main macro variables were reported: household consumption $(-0.0085 \%)$, investment $(-0.0404 \%)$, exports $(0.0009 \%)$. When GDP decreases after industries experience an increase in transportation cost, changes

\footnotetext{
${ }^{10}$ Horridge (2011) raises three points in defence of this assumption, to validate its credibility.
} 
from the income side can only be driven through labour. If labour decreases, and assuming capital is fixed, the capital-labour ratio increases. Prices for primary factors change to keep the capital-labour ratio constant in the short term after which investments adjust to the change in prices. Considering this change in primary factor prices and the adjustment in investments that followed, real investments decreased by the greatest amount amongst main macro variables. Imports in TERM are a function of total demand by final users of goods and services, more commonly referred to as commodities. We have assumed that government expenditure is fixed in the short term and that those final users defined as exporters do not demand any imported commodities in their final usage stage (exporting commodities). It follows that a reduction in household and investment demand then decreases imports.

From the initial shock which increased the cost of transportation for industries in each province the following sectors experienced the largest relative cost increases: gold, textiles, clothing and footwear, electrical machinery and apparatus, and radio and television products. The average transport cost increase for these sectors in those provinces that contain them were $8.43 \%, 4.56 \%$, $5.25 \%, 3.81 \%$ respectively. Considering each province's increase in the weighted total transportation cost, Limpopo, North-West and Gauteng had the largest increases, $0.60 \%, 0.59 \%$ and $0.55 \%$ respectively.

From Haddad and Hewings (2004), the causal relationship that occurs when transport costs increase, raises the amount of transportation services required per unit of output, as well as adding upward pressure on the prices of composite commodities. In our results most commodities experienced price increases which indicate that on an aggregate level the increase in costs (first round price effects) outweighed the decrease in demand (second round price effects. Those sectors that saw the greatest increase in their prices include: glass and non-metals, metal and machinery, electrical equipment and apparatus, and coal. The average provincial price increase for each sector was: $0.026 \%, 0.018 \%, 0.011 \%$, and $0.008 \%$ respectively. Industries that experience the greatest decline in output include: transport services $(-0.051 \%)$, metal and machinery $(-0.036 \%)$, glass and non-metals $(-0.027 \%)$, construction $(-0.026 \%)$, and the gold sector $(-0.023 \%)$.

As an initial step to evaluate the effect of increasing transport costs on industries in various provinces, we compared the transport cost shock that each province experienced with the loss of GDP in that province. After the comparison we weighed the severely impacted sectors in each province against their relative share of total output in the province, to obtain each severely impacted sector's contribution towards the loss in GDP. This initial step brought the following provinces under our attention: Free State, Mpumalanga, Limpopo and Gauteng. The Free State had the largest consistent increases in transport costs, but their GDP loss was only the third largest. The main reason for the Free State's relatively small decline in GDP is that those industries that were most severely hit by transport cost increases, represent only $17.15 \%$ of their output (the smallest share amongst provinces). The decline in GDP from these sectors however, contributes $96 \%$ of the $0.010 \%$ loss in the Free State's GDP. Similarly it can be shown that Mpumalanga saw the second largest consistent increase in 
transport costs, but the largest reduction in GDP. Gauteng experienced the second largest decline in GDP even though consistent increases were rather muted, total weighted increases however, was the third largest. Limpopo's decline in GDP was only the fourth largest.

\subsection{Transport Services}

Our shock was directly applied to transport services, increasing the cost across all regions, which initially increased the relative price and reduced the demand for those services that finally lead to a consistent reduction in output of the commodity. Except for the direct application of the shock, first and second round effects weighed down on the production of transport services which now cost more per unit of production. Households who use the largest share of transport services $(21.16 \%)$, experienced a reduction in real income, which in turn reduced their use of transport services. Overall, firms, who are less competitive after a transport cost increase, produce less, which further reduces the demand for transport services that facilitate the flow of commodities. The greatest share of transport services are sourced from the region they are produced in; on average each province consumes $80.63 \%$ of transport services that are produced in the originating province. From the direct cost increase and the nature of consuming transport services in the originating province, all provinces saw a consistent decrease in transport services. Those provinces with a smaller decrease of transport services were aided by relatively smaller price increases (or large price decreases) of transport services; these provinces in turn saw an increase in the export of transport services to those provinces with higher price increases (or small price decreases). Mpumalanga saw the largest decrease in prices and henceforth the greatest export of transport services to other provinces like the Free State and Limpopo.

\subsection{Coal}

In the production of coal the main inputs are: transport services (38\%), petrochemical products (14\%), and metal and machinery manufactured goods $(12 \%)$. These sectors experienced substantial decreases in output after transport costs were increased, which added upward pressure on the prices of these commodities. The decrease in availability of coal production inputs, as well as relative price increases of those inputs, reduced coal output. Provinces that produce the largest share of coal are Mpumalanga (79.59\%), Limpopo (18.21\%) and Kwazulu-Natal (2.20\%). Kwazulu-Natal experienced the greatest decline in coal output; the relatively large decline is mostly a direct result of higher initial transport cost increases. Transport cost in Kwazulu-Natal increased $0.84 \%$, compared to $0.23 \%$ and $0.10 \%$ in Mpumalanga and Limpopo; which increased the commodity price for coal by the greatest amount in Kwazulu-Natal. Higher coal prices reduce the domestic demand for those goods which in turn reduces output. Users that demand coal (93\% of all domestic coal output) include: exporters $(43 \%)$, producers and distributors of electricity (16\%), manufacturers 
of metal and machinery (17\%) and petro-chemical producers (17\%); these users reduced their total demand by $0.0218 \%$. Although exports edged up marginally after transport costs increased, due to a decline in aggregate prices in the economy, coal only contributes $3.75 \%$ of total exports. Adjusting for the coal sector's weight of total exports, the sector only saw a $0.00003 \%$ increase in production to fill export demand. However, key producers that demand roughly $50 \%$ of coal as input, namely producers and distributors of electricity, manufacturers of metal and machinery as well as petro-chemical manufacturers, reduced their demand for coal by roughly $0.0109 \%$.

\subsection{Construction}

A decline in the production of construction goods as well as metals and machinery products, can best be explained by the investment decline, which declined by the greatest amount amongst main macro variables. Investors demand 36\% of commodities from the construction sector, and $29 \%$ from metals and machinery products, as inputs. It follows that a substantial decrease in investments, decreases the demand and henceforth output of these sectors. The consistent decline in the construction sector is further explained by the inputs that are used in production of those construction goods and services: construction $(30 \%)$, glass and non-metals (15\%), metal and machinery (12\%) and electrical machinery and apparatus (9\%). As the construction sector consumes $30 \%$ of the goods it produces, factors which initially weigh down output also indirectly weighs down the largest production input. The glass and non-metals, metal and machinery, as well as the electrical machinery and apparatus sectors, experienced the greatest increase in prices. Higher prices in these sectors weighed down on the production capabilities of the construction sector (increasing the cost of producing each unit) which in turn reduced their demand for those commodities. Following the same argument, a decline in investments decreases the demand for metals and machinery products, which are $29 \%$ of the inputs used by investors. The metals and machinery sector consumes $46 \%$ of the goods it produces; once again factors which initially weigh down output also indirectly weighs down the largest production input in the metals and machinery sector.

\subsection{Gold}

Transport costs in the gold sectors of Gauteng, Kwazulu-Natal and the Free State increased by the greatest amount: $11.18 \%, 7.37 \%$ and $6.75 \%$, respectively. Overall, these transport cost increases were relatively large compared to other commodities, which, as we have discerned from our data, stems from the nature of transporting precious metals. Precious metals are very rarely transported in tonnes like other commodities; this increased the number of travelled routes required to facilitate the trade of precious metals. More routes in turn increased the usage of the GFIP where E-tolls were levied. Output in the gold sector of these provinces was reduced by $0.048 \%, 0.036 \%$ and $0.028 \%$ respectively. Relatively large increases in transport costs, increased cost of producing gold 
in a particular province and finally reduced output in the relevant province. However, in our application of TERM, we have assumed all unrefined gold is exported. The gold sector contributes $7.68 \%$ of total exports; adjusting for the gold sector's weight, output in the sector increased with $0.0001 \%$. The small output gain from export demand, explains the increase in gold sector output for those gold producing provinces that did not see relatively high price increases from transport cost increases: North West and Mpumalanga. In absolute terms the increase in output from North West, Mpumalanga and Limpopo (35\% of the sector), did little to offset the substantial decreases in output from Gauteng and Free State which dominate $40 \%$ and $25 \%$ of the sector, respectively. Therefore, concerning the entire gold sector, total output decreased.

\subsection{Real Income and Household Demand}

Through the causal relationship, higher commodity prices reduce household's real income, which in turn reduce their demand. From our initial assessment of GDP reductions we anticipated that provinces with larger GDP reductions would experience larger household demand reductions. When measuring the combined contribution to real income GDP, labour contributed the greatest amount to the decline in real income, particularly in Gauteng (-0.0031\%), Kwazulu-Natal $(-0.0013 \%)$ and the Western Cape $(-0.001 \%)$. The main reason behind the size of these reductions in real income, originates from each province's relative share of total employment, rather than a weighted share of employment. Changes in the real wage bill give a more weighted share of labour income. Sectors that reduced their demand for labour saw the wage bill decrease by the greatest amount in the following occupancies: operators, craftsmen and agricultural workers. On average the wage bill decreased by $0.039 \%$, $0.030 \%$ and $0.029 \%$ in each province for these occupancies respectively. Overall Mpumalanga saw the greatest decline in their real wage bill, followed by Gauteng, Limpopo and the Free State, as labour in these provinces have the largest share of operators, craftsmen and agricultural workers. These provinces experienced the greatest decline in household demand. The total decline in the wage bill for each of these provinces was $0.368 \%, 0.290 \%, 0.283 \%$ and $0.240 \%$ respectively.

Households in TERM demand commodities from two broad categories: subsistent and luxury. Changes in the demand for subsistent commodities occurred when the number of households changed (assumed constant in the short term) whilst the demand for luxury commodities were primarily driven by changes in the relative prices and their elasticities. Lower real income reduced total household demand; with lower household, investment and import demand (as noted earlier), aggregate demand in the economy decreased and aggregate prices followed suit. Lower aggregate prices, that is also evident in the reduction of consumer price inflation $(-0.10 \%)$, increased exports.

The demand for textiles, clothing and footwear barely decreased even though the initial transportation shock to the sector was the second greatest amongst all sectors. The nature of subsistent commodities allowed those high transport 
cost increases to be translated into muted, though consistent, price increases in all provinces. The sector has the smallest expenditure elasticity of all sectors; even though prices in the sector increased consistently in all provinces and real income decreased, household demand remained resilient. Household demand for glass and non-metal manufactured goods as well as radio and TV products, decreased by the greatest margin amongst commodities. The average provincial decrease in household demand for the sectors was $0.030 \%, 0.022 \%$ respectively.

The commodity price for glass and non-metal products increased by the greatest amount among commodities. However, the initial transport cost increase in the sector was relatively muted; high price increases were rather driven by second and third round price effects. The sector supplies $46 \%$ of its production to the construction sector; which, as we have explained, experienced consistent output reductions. Lower demand reduces output in the glass and non-metal sector and eventually prices in the sector increases. In the process of manufacturing glass and non-metals commodities, inputs from the following sectors are used: other mining (33\%), glass and non-metals (13\%) and transport services $(9 \%)$. Prices in the other mining sector increased moderately, but by the greatest amount in Gauteng (twice as large as other provinces) where $51 \%$ of all glass and non-metal machinery commodities are produced. As the glass and non-metals sector use $13 \%$ of the goods it produces, factors which initially increase prices in the sector also indirectly increase prices by adding upward pressure on input costs. Increases in the prices of input commodities caused the glass and non-metals sector to be less competitive, this reduced supply of the sector, and higher prices followed. Finally, high prices and a relatively large expenditure elasticity (fourth largest amongst commodities) caused household demand for glass and non-metal commodities to decrease by the greatest consistent amount amongst commodities. On average households in each province reduced their demand for glass and non-metal manufactured commodities by $0.03 \%$.

Household demand for radio, TV and communication commodities decreased by the second largest amount of all commodities, but this commodity did not experience severe price increases similar to other commodities. The reason for subtle price increases is due to $87 \%$ of the sector being imported; lower household demand was rather driven by other factors. These two sectors have the largest expenditure elasticities of all commodities, namely 1.85. Large expenditure elasticities allow even a slight decrease in household income to substantially decrease household demand for those commodities.

\section{Conclusion and Further Research}

This study evaluated the short term economic impact of a direct transport cost increase on industries after the introduction of E-Tolls. Through the causal relationship higher transport costs increased commodity prices, which reduced output in the economy. Commodity prices increased as a result of first round price effects. Second and third round price effects went in both directions, 
the net effect was determined by two substitution effects and an income effect. Producers experienced an increase in their production costs when the cost of transporting commodities increased per unit of output. A reduction in their competitiveness followed. Investors anticipated lower returns as the cost of producing capital increased, and households experienced relatively lower real incomes, and fewer consumption possibilities followed (Haddad and Hewings, 2004).

We conclude that the overall economic impact on household consumption, exports, imports and GDP is negligible. Aggregate prices declined by $0.1 \%$, which is quite small when considering how broad the increase in prices were; we found that most industries in each province experienced transport cost increases. Further, aggregate employment decreased with $0.2 \%$, which is negligible when considering broad cost increases and the current high unemployment level of $25.4 \%$ in South Africa (STATSSA, 2014). From our research we conclude that the increase in transport costs as a result of levying E-tolls, is relatively small in comparison to the total transport cost of physically moving commodities; this is the largest contributing factor to negligible changes in main macro variables. Compared to changes in other main macro variables, investments decreased by a relatively large amount namely $-0.04 \%$, but even here two important factors have to be taken into consideration. Firstly, in our short term focus we assumed that transport cost increases are driven through labour adjustments and capital was assumed fixed. Later research can evaluate the longer term and even dynamic impact of increasing industries' transport costs. Secondly, this study did not take into account the initial investment of the GFIP, R19.5 billion, as our focus was rather on measuring the short term impact of increasing industries' transport costs.

GDP decreased by the greatest amount in Mpumalanga $-0.014 \%$, Gauteng $-0.012 \%$, and in the Free State and Limpopo $-0.010 \%$. We anticipated that these provinces would experience larger household demand reductions through first and second round price effects that decreases household's real income, and henceforth demand for certain commodities. What is interesting is that Mpumalanga's reduction in GDP is $17 \%$ greater than that of Gauteng, and $31 \%$ greater than Limpopo and the Free State. We found that provinces that are closer to Gauteng make more frequent use of the GFIP than other provinces; these provinces experience relatively larger transport cost increases and henceforth larger GDP reductions. Apart from each province's use of the GFIP, another major reason for the relative size in regional GDP reductions originate from the share of severely hit industries in each province. This brought Mpumalanga, Gauteng, Limpopo and the Free State under our attention.

Overall Mpumalanga saw the greatest decline in its real wage bill, followed by Gauteng, Limpopo and the Free State (similar to the order of GDP reductions). These provinces have the largest share of operators, craftsmen and agricultural workers; occupancies that were most severely hit. The decline in the real wage bill for each of these provinces was relatively large compared to their GDP reductions: $0.37 \%, 0.29 \%$, and $0.24 \%$ respectively. Given the large reduction in real income, these provinces experienced the greatest decline in household de- 
mand, as we anticipated. Changes in the demand for subsistent commodities occurred when the number of households changed, whilst the demand for luxury commodities were primarily driven by changes in the relative prices and their elasticities. Household demand decreased by the greatest amount for the following commodities: glass and non-metal products $(0.27 \%)$, radio and TV products $(0.20 \%)$ and hotels $(0.11 \%)$. High prices and a relatively large expenditure elasticity caused household demand for glass and non-metal commodities to decrease by the greatest consistent amount amongst commodities. Household demand for radio, TV and communication commodities decreased by the second largest amount amongst all commodities, but this commodity did not experience severe price increases similar to other commodities. The reason for subtle price increases is a result of $87 \%$ of the sector being imported. Here, lower household demand was rather driven by household's expenditure elasticity for these goods, which was the highest amongst all commodities, namely 1.85.

Severely hit sectors include transport, metal and machinery, glass and nonmetals, construction and gold. The total decline in these sectors were $-0.051 \%$, $-0.036 \%,-0.027 \%,-0.026 \%$, and $-0.023 \%$ respectively. Our shock was directly applied to transport services, increasing the cost across all regions, which initially increased the relative price and reduced the demand for those services that finally lead to a consistent reduction in output of the commodity. Except for the direct application of the shock, first and second round effects weighed down further on the production of transport services. These effects include households, who consume the largest share of transport services $(21.16 \%)$, which experienced a reduction in real income from the shock, which in turn reduced their use of transport services. Overall, firms, who are less competitive after a transport cost increase, produce less, which further reduces the demand for transport services that facilitate the flow of commodities. From the direct cost increase and the nature of consuming transport services in the originating province, provinces experienced a consistent decrease in transport services.

Investments decreased by the greatest margin amongst main macro variables, $-0.04 \%$. Investors in turn demand $36 \%$ of commodities from the construction sector, and $29 \%$ from metals and machinery products, as inputs. It follows that a substantial decrease in investments decreases the demand and henceforth output of these sectors. The consistent decline in the construction sector is further explained by the inputs that are used in production of those construction goods and services: construction (30\%), glass and non-metals (15\%), metal and machinery (12\%). As the construction sector consumes $30 \%$ of the goods it produces, investments which initially weighs down output also indirectly weighs down the largest production input.

Transport costs in the gold sectors of Gauteng, Kwazulu-Natal and the Free State increased by the greatest amount amongst all sectors: $11.18 \%, 7.37 \%$ and $6.75 \%$ respectively. These relatively large transport cost increases, originate from the nature of transporting precious metals. Large transport cost increases, increased the cost of producing gold in a particular province and finally reduced output in the relevant province. Output in the gold sector of these provinces was reduced by $0.048 \%, 0.036 \%$ and $0.028 \%$ respectively. 
Although it was not part of our initial research we have also estimated the changes in indirect costs or benefits on industries and consumers. ${ }^{11}$ Simulating our initial direct costs on industries with the technological advancement brought on by the GFIP, and including the direct and indirect costs and benefits to the consumer, a more complete impact on the economy can be evaluated. However, there are two major shortcomings which can be overcome in further research. Firstly, we are only evaluating the short term impact where technology is assumed fixed; a better approach would be to simulate these shocks in the long term. Secondly, the current TERM model is static and does not allow shocks to impact one another in a dynamic manner as time progresses. These shortcomings can partially be overcome by running two separate simulations: a short term simulation for changes in costs and a longer term simulation for changes in technology that incorporates short term changes. However, the lack of dynamics would still not be bridged. Once again our focus is rather on evaluating the short term impact of transport cost changes. Taking this into consideration, the short term impact of direct and indirect costs and benefits to industries as well as consumers, after the GFIP was introduced and E-Tolls were levied, was simulated. The following changes in main macro variables occurred: consumer price inflation decreased with $0.12 \%$ and aggregate employment increased with $0.5 \%$. Other macro variables include: household consumption $(0.0505 \%)$, investments $(0.0158 \%)$, exports $(-0.0174 \%)$, imports $(0.0215 \%)$, and GDP $(0.0228 \%)$.

Finally, we can conclude that the short term impact of increasing industries' transport costs, as a result of levying E-Tolls, has a marginally negative impact on economic aggregates. However, when considering a more complete set of direct as well as indirect costs and benefits, the economic impact in the short term is positive, but still rather muted.

\section{References}

[1] Bröcker, J. A. K. \& Carsten, S., 2010. Assessing spatial equity and efficiency impacts of transport infrastructure projects. Transportation Research Part B: Methodological, 44(7), pp. 795-811.

[2] Das, G. G. et al., 2005. Regional impacts of environmental regulations and technical change in the US forestry sector: a multiregional CGE analysis. Forrest Policy and Economics, 7(1), pp. 25-38.

[3] Department of Transport, 2011. Gauteng Freeway Improvement Project Steering Committee Report. s.l.:s.n.

[4] Dixon, P., Parmenter, B., Sutton, J. \& Vincent, D., 1982. ORANI: A Multisectoral Model of the Australian Economy.. North-Holland, Amsterdam..

[5] Domingues, E. P., Haddad, E. A. \& Hewings, G. J. D., 2003. Sensitivity Analysis in Applied General Equilibrium Models: an Empirical Assess-

\footnotetext{
${ }^{11}$ These findings are available upon request from the author.
} 
ment for MERCOSUR Free Trade Areas Agreements. University of Illinois(Urbana): s.n.

[6] Donaghy, K. P., 2009. CGE modeling in space: a survey. In: Capello, Roberta, Nijkamp \& Peter, eds. Handbook of regional growth and development theories. s.l.:Edward Elgar, Cheltenham, pp. 389-422.

[7] Economists.co.za, 2011. Consumer impact of the Gauteng Freeway Improvement Program, s.l.: s.n.

[8] Glyn, W. \& Horridge, M., 2007. CGE modelling of the resources boom in Indonesia and Australia using TERM. Quenstown, New Zealand, s.n.

[9] Haddad, E. A. \& Hewings, G. J. D., 2004. Transportation Costs, Increasing Returns and Regional Growth: An Interregional CGE Analysis. s.l., s.n., p. 461.

[10] Havenga, J. H., 2007. The Development and Application of a Freight Transport Flow Model for South Africa. Stellenbosch University PhD Dissertation, p. 255.

[11] Havenga, J. H., 2013. The Importance of dissaggregated freight flow forecasts to inform transport infrastructure investments. Journal of Transport and Supply Chain Management.

[12] Horridge, M., 2003. ORANI-G: A generic Single-Country Computable General Equilibrium Model. Monash University, Australia, Centre of Policy Studies and Impact Project, pp. 1-83.

[13] Horridge, M., 2011. The TERM model and its data base. General Paper, July, Volume G-219, pp. 1-21.

[14] Horridge, M. J., 1999. A General Equilibrium Model of Australia's Premier City. Centre of Policy Sutdies, Preliminary Working Paper, Volume 74, pp. $1-19$.

[15] Horridge, M., Madden, J. \& Wittwer, G., 2005. The impact of the 20022003 drought on Australia. Journal of Policy Modelling, October, 27(3), pp. 285-308.

[16] Horridge, M. \& Wittwer, G., 2007. The Economic Impacts of a Construction Project, using SinoTERM, a Multi-regional CGE model of China. Centre of Policy Studies and the Impact Project, G(164).

[17] Ishiguro, K. \& Inamura, H., 2005. Identification and Elimimenation of Barriers in the Operations and Management of Maritime Transportation. Research in Transportation Economics, Volume 13, pp. 337-368.

[18] Latorre, M. C., Oscar, B.-R. \& Antonio, G. G.-P., 2009. The effects of multinationals on host economics: A CGE approach. Economic Modelling, 26(5), pp. 851-864. 
[19] Li, et al., 2009. Roles of Regional Differences and Linkages on Chinese Regional Policy Effect in CGE Analysis. Systems Engineering - Theory 86 Practice, 29(10), pp. 35-44.

[20] Lofgren, H., Rebecca, L. H. \& Sherman, R., 2002. A Standard Computable General Equilibrium (CGE) Model in GAMS, s.l.: International Food Policy Research Institute.

[21] National Treasury and SARS, 2013. Tax Statistics. pp. 1-207.

[22] Pienaar, P. A., 2011. Gauteng Toll Roads: An Overview of Issues and Perspectives. Pretoria, South Africa, s.n., pp. 697-710.

[23] Road Freight Association, 2013. Vehicle Cost Schedule. October.

[24] Sakamoto, H., 2012. CGE Analysis of Transportation Cost and Regional Economy: East Asia and Northern Kyushu. Regional Science Inquiry Journal, IV(1), pp. 121-140.

[25] SANRAL, 2013. Government Gazette. Gauteng Freeway Improvement Project, Toll Roads: Exemption from the Payment of Toll, 19 November, Issue 37038, pp. 43-48.

[26] Standish, B., Boting, A. \& Marsay, A., 2010. An Economic Analysis of the Gauteng Freeway Improvement Scheme, s.l.: Provincial Government of Gauteng \& SANRAL.

[27] STATSSA, 2013. Gross Domestic Product. Third Quarter 2013, pp. 1-75.

[28] Steininger, K. W., Friedl, B. \& Gebetsroither, B., 2006. Sustainability impacts of car road pricing: A computable general equilibrium analysis for Austria. Ecological Economics, 63(1), pp. 59-69.

[29] Ueda, et al., 2005. Spatial benefit incidence analysis of airport capacity expansions: Application of SCGE model to the Haneda Project. Research in Transportation Economics, Volume 13, pp. 165-196.

[30] Wittwer, G., 2003. An outline of TERM and midifications to include water usage in the Murray-Darling Basin, Victoria: s.n.

\footnotetext{
${ }^{1}$ TERM is an acronym for The Enormous Regional Model, for simplicity we refer to the TERM model.

${ }^{2}$ TERM is a bottom-up CGE model designed for highly disaggregated regional data. "CGE" is an acronym for Computable General Equilibrium. TERM models originate from Horridge et al. (2005) which are better explained in Horridge (2011).
} 